\title{
Referencing Paradigm in the New Norm: What Do Students Want?
}

\author{
Mohamad Rahimi Mohamad Rosman ${ }^{1}$, Nik Nur Izzati Nik Rosli², Amira Idayu Mohd \\ Shukry $^{3}$, Noor Masliana Razlan ${ }^{4}$, Noor Azreen Bt Alimin ${ }^{5}$ \\ \{rahimimr@uitm.edu.my ${ }^{1}$,izzati1233@uitm.edu.my², amira1220@uitm.edu.my ${ }^{3}$ \}
}

Faculty of Information Management, Universiti Teknologi MARA Kelantan Branch, Malaysia

\begin{abstract}
Referencing competency is the capability to effectively and efficiently managing sources of literature that enable forward and backward searching of the articles. Referencing competency enable easier access to the literature, ensure the integrity of publication and fostering academic discussion on a higher level. Nowadays, many tools, style, and technique has been developed for managing references, especially in dealing with the vast number of digital resources. However, since technologies on referencing change over time, thus there is always a need to revisit the surface of the user's preferences in dealing with reference sources. A quantitative research methodology was adopted, and findings were analysed based on descriptive using Statistical Package for Social Sciences version 26.
\end{abstract}

Keywords: Reference; Referencing; Behaviour

\section{Introduction}

According to Hoffmann [1], competency has not been clearly defined over the years. Two schools of thought relate competency with: (1) the output produces or outcome of certain training and (2) certain skills, attributes, or output required by an individual to achieve competent performance. The need for a competent workforce increases by over $6 \%$ per year [2]. Boyatzis [3] argue that competency relates to observable, measurable, and trainable attributes of an individual. Fulfilling these attributes should lead to superior work performance. In the landscape of academic work, engagement with digital resources helps a student to complete their information task more efficiently [4-5]. The capability to effectively use digital resources was seen as one of the factors that lead to research progress among students [4]. On the other hand, dealing with the complexity of tasks and unstructured resources required students to have the ability to effectively managing digital resources especially in relation to references management [6]. The competency on referencing helps a student to reduce information searching time, enhance academic integrity, and enable the continuation of knowledge [7].

However, much has changed since the introduction of referencing styles, standards, and techniques. On top of it, the pandemic of Novel Coronavirus 2019 (COVID-19) has seemed the surges to the dependency on digital library resources [8-11]. Thus, there is a compelling need to investigate and revisited the surface of the user's preferences in dealing with reference 
sources. This paper is structured as follows: First, we discuss the literature on referencing and competency. Next, we discuss the methodology underlining the study, before continuing with findings and discussion. Conclusion and limitations are presented at the end of the paper.

\section{Literature Review}

\subsection{Reference Tool}

Academic writing relies not only on the ideas and experience of one author but also based on the ideas and research of other sources that can be used to support the author's ideas. It can be used to discuss, analyse, or critic other sources. Referencing is used to tell the reader where ideas from other sources have been used in the writing [12]. Reference tools are any resource, program or service that supports referencing management, or the understanding, gathering, organization, and use of referencing in research [13]. Reference tools are good for writing articles or books, suitable also for collaboratively work that can protect the ideas of the authors. It can be used also for sharing the references and curate the collection of references [14].

There are four categories include reference managers, reference generators, reference guides and reference management education. Reference managers are also referred to as bibliographic or reference management software such as Endnote, RefWorks and Zotero that most commonly supported in academic libraries. Reference generators are web tools that help users generate formatted citations and bibliographies, it can be copied and paste into a document such as EasyBib, KniteCite and NoodleBib. Reference guides help users with rules, guidelines and examples for citation styles such as APA American Psychological Association, MLA Handbook and Chicago Manual of Style. Lastly, reference management education introduces concepts or tools in bibliographic instruction, classes on using citation or consultation with reference desk [13].

\subsection{Importance of References in an Academic Setting}

In an academic environment, reference is the most unique feature of language that is being used to cite other people's work which is basic for the strength and the acceptance of academic arguments [15-24]. Referencing is one of the important methods that are being used in order to help both students and educators in preventing themselves from plagiarise. Plagiarism can give serious consequences to students as well as academicians as it is one of the acts of dishonesty. Borg [25] stated that the failure to properly differentiate between one's own words and ideas and others can lead to plagiarism as it is a capital offence in academic settings.

In academic discipline, it is important to have a proper and appropriate reference. Good referencing can increase the credibility and reputation of the writers as it shows off their scientific knowledge, vice versa to poor referencing which will be interpreted as a sign of intellectual laziness, unclear thinking, and inaccurate writing [26]. Furthermore, reference will indicate the quality, credibility and authority of the materials that are being referred to in writing academic papers which provides the information about the authors and sources that were referred to [27]. According to Roig [28], reference is a very crucial service in scholarly and scientific writing as it helps the reader to explore more and in detail the evidence and topics discussed. 


\subsection{Digital Usage in the New Norm}

The spread of COVID-19 has forced educational institutions to move their communication online. This pandemic has restricted teaching and learning to fully online learning mode and forced the educational institution to global physical closure of businesses, sports activities and schools by pushing all institutions to migrate to online platforms [29]. For the foreseeable future, the world must adapt to a "New Norm" in which digitization, masking, and social distancing are the norm. Covid 19 and with the advent of ICTs has changed the ways of learning resources been used and access. It has changed the interest and focus of a large percentage of a university students on digital learning resources from printed material [30]. For a variety of reasons, digital learning resources are becoming more popular and important at all levels of education [31]. In general, most higher learning institutions in both developing and developed countries agree that e-resources promote teaching, learning, and research activities to a substantial amount [32].

Students nowadays more prefer using digital resources more than printed materials. This is due to the convenience and ease to access compared to printed materials that need a physical visit to the library. University students have made substantial use of resources such as slide presentations, recordings, online lectures, e-books, online tutorials, and learning management systems [33]. Although students believe library materials are truthful and reputable, they prefer to use web search engines because of their convenience, speed, and reliability [34]. Research done by Berzins \& Hudson [31] showed that there are various advantages of using digital resources among students, including more and faster access to content to enhance their learning and more involvement in face-to-face and blended teaching. However, the quality and variety of subscribed and open-access learning resources are the most important things that need to consider for the sake of facilitating academic activities [30].

\subsection{User Intention to Use DL Resources}

Matusiak [35] asserted academic libraries are actively involved in the current digital revolution by offering scholarly content in digital format over library websites and by the process of digitizing their unique collection of multimedia resources, visual and text. According to Mollel and Mwantimwa [36], the factors influencing the intention to use eresources in DL among users are different. According to the past literature, it was found that many factors influence the intention of users for the use of e-resources research, teaching and learning. User's intention to use DL resources depends on factors such as user perceptions, abilities, and facilitating circumstances [37]. Jeong [38] added ease of use is a major determinant of intentional behaviour. Additionally, Tao [39] wrote user's intention toward DL usage is fully influenced the perceived usefulness and perceived ease of use in terms of information quality and system quality. In connection with this, Hindagolla [40] reported system quality and contents' relevance influence the user's intention to use DL resources.

\section{Methodology}

The purpose of the study is to revisit the surface of users' behaviour and preferences in managing reference resources. Thus, the conduct of a quantitative study using a questionnaire is considered the best method to identify the descriptive nature of the research question. This study follows several empirical stages, as illustrated in Figure 1 below. 


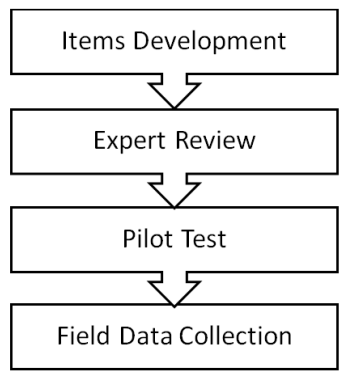

Fig. 1. Summary of research methodology

The research started with instrument development. Items were adapted from the previous study of Stevens and Campion [41], Kiran and Diljit [42], SFASU Knowledge, Skills, and Abilities (KSA) Bank [43], Abu-Dalbouh [44], and Surya [45]. Next, the instrument was submitted for an expert review process to ensure validity of the instrument. To guide the process of the instrument validation, The Content Validity Index (CVI) of Polit and Beck [46] was adopted. Items were then modified to meet the suggestion of the experts before the pilot test was conducted to determine the reliability of the instrument. A total of 50 participants was involved in the pilot study.

In relation to sampling, the study adopted a convenience sampling technique due to the difficulty to obtain the list of respondents. The respondents were selected from students at the Faculty of Information Management in Universiti Teknologi MARA. An ethics application was filed and granted before the data collection. A total of 394 valid responses were received and the data were analysed using Statistical Packages for Social Sciences (SPSS) version 26. The finding of the study will be elaborated further in the subsequent section.

\section{Results and Discussion}

\subsection{Results}

The following subsections explain the finding of the study. Respondents were asked using an open-ended and Likert scale questionnaire of 1 to 5 .

\subsubsection{Main Reference Sources}

Table 1 shows the main reference sources use by the respondents. The majority of respondents utilize non-Digital Library resources (i.e., search engines) such as Google and Yahoo!. In the second place is Google Scholar, one of the popular indexing databases of academic articles provided by Google Incorporation. On the other hand, two DL products which are EzAccess and MyKM portal was ranked third and fourth by the respondents, an indicator of their preference towards non-DL resources. Interestingly, ResearchGate was also ranked higher compared to the Directory of Open Access Journal (DOAJ).

Table 1. Main reference source

\begin{tabular}{cc}
\hline Reference Sources & Frequency \\
\hline MyKM Portal & 221 \\
EzAccess & 232 \\
\hline
\end{tabular}




\begin{tabular}{cc}
\hline Reference Sources & Frequency \\
\hline Google Scholar & 234 \\
Search Engine & 261 \\
ResearchGate & 138 \\
Open Access Journal & 129 \\
\hline
\end{tabular}

\subsubsection{Preferable Reference Tools}

Table 2 shows the preferable reference tools as indicated by the respondents. As expected, EndNote was ranked the highest by respondents, followed by Mendeley and EasyBib. RefWorks and Zotero were also ranked, however, it seems that respondents have limited knowledge of these two selected reference tools. On top of that, several respondents acknowledge that they did not have any knowledge regarding reference tools, thus selected to be undecided.

Table 2. Preferable reference tools

\begin{tabular}{cc}
\hline Reference Tool & Frequency \\
\hline EndNote & 204 \\
Mendeley & 153 \\
EasyBib & 120 \\
RefWorks & 26 \\
Zotero & 2 \\
Undecided & 7 \\
\hline
\end{tabular}

\subsubsection{Frequency to Check the Accuracy of Citation}

Table 3 shows the frequency of respondents in checking the accuracy of the citation or references. The findings indicate that most respondents are unsure of the accuracy of the citation download from the Internet. Only a small percentage of 1.3 percent have the utmost belief in the citation that the found on the Internet, while others tend to recheck the accuracy of the citation.

Table 3. Frequency of checking the accuracy of citation

\begin{tabular}{cc}
\hline Indicator & Frequency \\
\hline Never & 5 \\
Rarely & 63 \\
Sometimes & 186 \\
Often & 89 \\
Always & 51 \\
\hline
\end{tabular}

\subsubsection{Engagement with Reference Librarian}

Table 4 shows the frequency of engagement between respondents and reference services (i.e., reference librarians) provided by their local library. Intriguingly, the majority of respondents agreed that their level of engagement is relatively poor; 29.6 percent of respondents acknowledged that they never had any kind of engagement with the reference librarian, while $42.9 \%$ were rarely in contact with the reference librarian.

Table 4. Engagement with a reference librarian

\begin{tabular}{cc}
\hline Indicator & Frequency \\
\hline Never & 117 \\
Rarely & 169 \\
\hline
\end{tabular}




\begin{tabular}{cc}
\hline Indicator & Frequency \\
\hline Sometimes & 95 \\
Often & 10 \\
Always & 3 \\
\hline
\end{tabular}

\subsubsection{Knowledge of Information Skills Class Provided by the Library}

Table 5 shows the respondent knowledge of the information skills class provided by the library. The findings show a tendency towards positive responses, in which the majority of respondents agreed that they know and are aware of the information skills class provided by the library. The findings also illustrated that only 73 respondents have a negative response indicating that they are not aware of the library services on information skill class.

Table 5. Knowledge of information skills class provided by the library

\begin{tabular}{cc}
\hline Indicator & Frequency \\
\hline Definitely Not & 20 \\
Probably Not & 53 \\
Possibly & 112 \\
Probably & 112 \\
Definitely & 97 \\
\hline
\end{tabular}

\subsubsection{Tendency to Spend Time to Check Accuracy of References}

Table 6 shows the amount of time that respondent spent checking the accuracy of the references. Interest, the finding indicating that respondents spent a lot of time checking the accuracy of the references even though they have been provided by many tools that can simplify references management, such as EndNote, Mendeley, etc.

Table 6. Tendency to spent time to check the accuracy of references

\begin{tabular}{cc}
\hline Indicator & Frequency \\
\hline Did Not Bother & 20 \\
Less than 10 minutes & 81 \\
10 to 15 minutes & 160 \\
30 minutes and above & 133 \\
\hline
\end{tabular}

\subsection{Discussion}

The study revisited the student's preferences in managing references resources. Several interesting findings were found and warrant further discussion. First, this study found that students in higher education prefer to use non-DL resources as their main reference tools. This finding is similar to the finding of previous studies that indicate libraries are having difficulty justifying their investment in digital library resources due to lack of usage. On the other hand, referring or utilizing non-DL resources may jeopardize the quality of work being produced, as well as the authenticity and authority of academic works.

Second, knowledge of reference tools is mandatory for a university student. Our findings indicated that a certain minority of students especially new students were having difficulties or lack of knowledge on the functions and benefits of the reference tools. Moreover, most students are not exposed to different kinds of reference tools and their knowledge are limited to mainstream software only such as EndNote and Mendeley. 
Third, utilising reference tools does not guarantee accurate citation and it has been acknowledged by the result of this study in which respondents take their own initiative to check the accuracy of references downloaded from the Internet. Moreover, the problem could be associated with the tendency of a respondent to utilize non-DL resources that usually provide incomplete citation compared to well established online databases provider such as Scopus, Emerald, IEEE Xplore, etc.

Fourth, lack of engagement between library patron (university student) and reference librarian is considered as one of the stumbling blocks in information system usage, particularly related to digital library resources. New norm digital interactivity requires constant engagement between both parties to ensure continuing usage of digital library resources and promote loyalty among the users. However, our finding indicates that students are having problems engaging themselves with the reference librarian. Thus, it suggested that the library take proactive action to encourage engagement such as webinars, library open days, mentoring, etc. Besides, since students already knew regarding the information skills class provided, a yearly seminar between librarian and students is the best way to promote constant engagement.

\section{Conclusion}

The study was conducted to revisit the preferences of users in managing references resources. A quantitative research methodology was adopted, and the findings of the study are analysed using Statistical Package for Social Sciences (SPSS) version 26 via descriptive analysis. The finding then describes briefly and important issues were highlighted in the discussion section. The limitation of the study is as follows: first, the respondents of the study were selected from a single university. Future studies may consider collecting data from multiple universities to further enhance the result of the study. Second, the respondents were selected from the faculty that specialize in information management. Future studies may consider other types of faculties especially those with limited knowledge of reference management. Third, this study focuses on the descriptive nature of the findings, future studies may consider investigating other factors that lead to reference management preferences among students. However, underneath this limitation, we can conclude that this study has met its purposes and added the knowledge on user preferences in using references resources in the context of Malaysian universities students.

\section{Acknowledgements}

The authors would like to thank the financial support received from Universiti Teknologi MARA Kelantan Branch under Geran Dalaman 600-TNCPI 5/3/DDN (03) (004/2020).

\section{References}

[1] Hoffmann, T. (1999). The meanings of competency. Journal of European industrial training, 23 (6), 275-286.

[2] Walker, P., Hein, K., Russ, C., Bertleff, G., \& Caspersz, D. (2010). A blueprint for professionalizing humanitarian assistance. Health Affairs, 29(12), pp. 2223-2230. 
[3] Boyatzis, R. E. (1982). The competent manager: A model of effective performance, New York, NY: John Wiley \& Sons.

[4] Khan, A., \& Ahmed, S. (2013). The impact of digital library resources on scholarly communication: challenges and opportunities for university libraries in Pakistan. Library Hi Tech News, 30 (8), 12-29.

[5] Mohamad Rosman, M. R., Ismail, M. N., \& Masrek, M. N. (2021). Investigating the Predictors of Digital Library Engagement: A Structured Literature Analysis. Pakistan Journal of Information Management and Libraries, 22, 60-82.

[6] Mohamad Rosman, M. R., Ismail, M. N., \& Masrek, M. N. (2021). How Engaging Are You? Empirical Evidence from Malaysian Research Universities. International Journal of Interactive Mobile Technologies, 15(4).

[7] Mohamad Rosman, M. R., Shukry, A. I. M., Alimin, N. A., Baharuddin, N. S., Nik Rosli, N. N. I., \& Razlan, N. M. (2021). Level of Individual Performance in the Context of Referencing Competency. In: ICLSSEE 2021, March 6th 2021, Jakarta, Indonesia.

[8] S Baharuddin, N., \& Mohamad Rosman, M. R. (2020). Factors affecting the usage of Library e-services in the aftermath of COVID-19 Pandemic. Academic Journal of Business and Social Sciences (AJoBSS), 4(1), 1-14.

[9] Asimah, A. P. A., Dzogbede, O. E., \& Akaba, S. (2021). Digital Library Usage during the Covid-19 Pandemic. Library Philosophy and Practice, 1-15.

[10] Ćirić, J., \& Ćirić, A. (2021). The Impact of the COVID-19 Pandemic on Digital Library Usage: A Public Library Case Study. Journal of Web Librarianship, 1-16.

[11] Mohamad Rosman, M.R., \& S Baharuddin, N. (2021). Are we using enough library eservices Investigating the level of library e-services usage among students. In Proceedings of International Conference on Language, Education, Humanities \&Social Sciences (i-LEdHS2021), 22 Febuari 2021, UiTM Cawangan Kelantan.

[12] Massey University. (2010). What is referencing? Retrieved from https://owll.massey.ac.nz/referencing/what-is-referencing.php

[13] Childress, D. (2011). Citation tools in academic libraries: Best practices for reference and instruction. Reference \& User Services Quarterly, 51(2), 53-62. Retrieved from https://www.jstor.org/stable/refuseserq.51.2.143? =1462272573002

[14] Stokes, D. (2014). Using reference management tools: Endnote and zotero [PowerPoint slides]. Slideshare. https://www.slideshare.net/eservice/using-42828887

[15] Jomaa, N. J., \& Bidin, S.J. (2017). Perspective of EFL doctoral students on challenges of citations in academic writing. Malaysian Journal of Learning and Instruction (MJLI), 14 (2), 177-209.

[16] Hewings, A., Lillis, T., \& Vladimirou, D. (2010). Who's citing whose writings? A corpus-based study of citations as interpersonal resource in English medium national and English medium international journals. Journal of English for Academic, 9(2), 102115.

[17] Mansourizadeh, K., \& Ahmad, U. K. (2011). Citation practices among non-native expert and novice scientific writers. Journal of English for Academic Purposes, 10(3), $152-161$.

[18] Monreal, C. S., \& Salom, L. G. (2011). A cross-language study on citation practice in $\mathrm{PhD}$ theses. International Journal of English Studies, 11(2), 53-75.

[19] Nguyen, T. T. L., \& Pramoolsook, I. (2015). Citation in Vietnamese TESOL: Analysis of master's thesis introduction chapters. The Asian ESP Journal, 2(1), 95-184. 
[20] Rowley-Jolivet, E., \& Carter-Thomas, S. (2014). Citation practices of expert French writers of English: issues of attribution and stance. In A. Lyda and K. Warchal (Eds.), Occupying niches: Interculturality, cross-culturality and aculturality in academic research (pp.17-34). Springer International Publishing.

[21] Samraj, B. (2013). Form and function of citations in discussion sections of master's theses and research articles. Journal of English for Academic Purposes, 12(4), 299310.

[22] Shooshtari, Z. G., \& Jalilifar, A. (2010). Citation and the construction of subdisciplinary knowledge. The Journal of Teaching Language Skills (JTLS), 2(1), 4566.

[23] Swales, J. M. (2014). Variation in citational practice in a corpus of student biology papers: From parenthetical plonking to intertextual storytelling. Written Communication, 31(1), 118-141.

[24] Thompson, P., \& Tribble, C. (2001). Looking at citations: Using corpora in English for Academic Purposes. Language Learning and Technology, 5(3), 91-105.

[25] Borg, E. (2000). Citation practices in academic writing. Retrieved from https://www.researchgate.net/publication/313443669_Citation_practices_in_academic_ writing/link/5aa64e71aca272d448badeb1/download

[26] Santini, A. (2018). The importance of referencing. The Journal of Critical Care Medicine, 4(1):3-4. https://doi.10.2478/jccm-2018-0002

[27] University of Otago. (2017). What is referencing and why is it important? Retrieved from https://www.otago.ac.nz/hedc/otago615365.pdf

[28] Roig, M. (2006). Avoiding plagiarism, self-plagiarism, and other questionable writing

[29] Adedoyin, O. L \& Soykan, E. (2020). Covid - 19 pandemic and online learning: the challenges and opportunities. Interactive Learning Environments. Retrieved Jun 18, 2021 from https://doi.org/10.1080/10494820.2020.1813180

[30] Alphonce, S. \& Mwantimwa, K. (2019). Students' use of digital learning resources: diversity, motivations and challenges. Information and Learning Sciences, 120(11/12), 758-772. DOI 10.1108/ILS-06-2019-0048

[31] Bernzins, K. \& Hudson, A. (2011). The Use of e-Resource: the snapshot of e-Resource use among Linking London LNN Partner Institution. University of East London

[32] Henderson, M., Selwyn, N. \& Aston, R. (2017). What works and why? Student perceptions of useful digital technology in university teaching and learning. Studies in Higher Education, 42(8), 1567-1579.

[33] Selwyn, N. \& Gorard, S. (2016). Students' use of Wikipedia as an academic resource: patterns of use and perceptions of usefulness. The Internet and Higher Education, 28, 28-34.

[34] Holman, L. (2011), “Millennial students' mental models of search: implications for academic librarians and database developers", The Journal of Academic Librarianship, Vol. 37 No. 1, pp. 19-27.

[35] Matusiak, K. K. (2012). Perceptions of usability and usefulness of digital libraries. International Journal of Humanities and Arts Computing, 6(1-2), 133-147. https://doi.org/10.3366/ijhac.2012.0044

[36] Mollel, M. M., \& Mwantimwa, K. (2019). Users ' acceptance of e-resources usage at the Institute of Finance Management, Tanzania Mumitie Moikan Mollel Mwenge Catholic University, Tanzania Kelefa Mwantimwa University of Dar es Salaam , Tanzania. 
[37] Arshad, A., \& Ameen, K. (2018). Usefulness of Ejournals Consortium in Pakistan: Academic Staff's Perceptions and Expectations. Https://Doi.Org/10.1080/00987913.2018.1506073, 275-281. https://doi.org/10.1080/00987913.2018.1506073

[38] Jeong, H. (2013). An investigation of user perceptions and behavioral intentions towards the e-library. Https://Doi.Org/10.1080/14649055.2011.10766298, 35(2-3), 4560. https://doi.org/10.1080/14649055.2011.10766298

[39] Tao, D. (2009). Intention to Use and Actual Use of Electronic Information Resources: Further Exploring Technology Acceptance Model (TAM). AMIA 2009 Symposium Proceedings, 629.

[40] Hindagolla, M. (2014). Understanding User Acceptance of Electronic Information Resources : Effects of Content Relevance and Perceived Abilities. 59, 239-255.

[41] Stevens, M. J., \& Campion, M. A. (1994). The knowledge, skill, and ability requirements for teamwork: Implications for human resource management. Journal of management, 20(2), 503-530.

[42] Kiran, K., \& Diljit, S. (2012). Modeling web-based library service quality. Library \& Information Science Research, 34(3), 184-196.

[43] SFASU Knowledge, Skills, and Abilities (KSA) Bank. (2012). Retrieved December 1, 2020, from http://www.sfasu.edu/hr/documents/KSA_Bank_Form_2012.docx

[44] Abu- Dalbouh, H.M., (2013). A questionnaire approach based on the technology acceptance model for mobile tracking on patient progress applications. Journal Computer. Science, 9(6), 763-770.

[45] Surya, W. A. (2014). Pengaruh Employee Knowledge, Skill, Dan Ability (KSA) Terhadap Penggunaan Sistem Informasi Sumberdaya Manusia Dan Kinerja Karyawan. Jurnal Administrasi Bisnis, 8(1). Retrieved from http://administrasibisnis.studentjournal.ub.ac.id/index.php/jab/article/view/351

[46] Polit, D. F., \& Beck, C. T. (2006). The content validity index: are you sure you know what's being reported? Critique and recommendations. Research in nursing \& health, 29(5), 489-497. 